\title{
CODICOLOGIA, HISTÓRIA E CULTURA
}

\author{
CODICOLOGY, HISTORY AND CULTURE
}

\author{
CODICOLOGÍA, HISTORIA Y CULTURA
}

Ubirajara Alencar Rodrigues

\section{RESUMO}

Este artigo versa sobre a Codicologia, como disciplina, e aborda algumas características visuais dos livros manuscritos, em especial árabes e persas, exploradas nesse campo de estudos. Essas características podem ser identificadas como uma cultura visual. Visita também algumas experiências de profissionais que desenvolveram atividades na Biblioteca Nacional da França, onde há um departamento específico para o cuidado e conservação de diversas coleções de livros manuscritos, originárias de várias culturas, como árabes e persas. Essas experiências têm intima relação com a Codicologia.

PALAVRAS-CHAVE: Codicologia. História do livro manuscrito. Cultura visual. Coleções de livros manuscritos. Biblioteca Nacional da França.

\section{ABSTRACT}

This article says about Codicology, as a discipline and cover some visual characteristics of the manuscript books, in special Arabian and Persian, analyze in this field of studies. These characteristics can be identify as a visual culture. Visit also some experiences of profissionals who developed activities in France National Library, where there is a specific department to take care and conversation of varities colletions of manuscript books, from many cultures, as Arabian and Persian. These experiences have a close relationship with a Codicology.

KEYWORDS: Codicology. History of manuscript. Visual culture. Collections of manuscript books. National Library of France.

\section{RESUMEN}

Este artículo trata de la Codicología, como diciplina, y aborda algunas características visuales de los livros manuscritos, en especial arabes y persas, explorados en este campo de estudios. Esas características pueden ser identificadas como una cultura visual. Visita tambien algunas experiencias de profesionales que desarrollaron actividades en la Biblioteca Nacional de Francia, donde hay un departamento especifíco para el cuidado y conservación de diversas colecciones de libros manuscritos, originarios de varias culturas, como arabes y persas. Esas experiencias tienen intima relación con la Codicología.

PALABRAS-CLAVE: Codicología. Historia del libro manuscrito. Cultura visual. Colecciones de libros manuscritos. Biblioteca Nacional de Francia.

\section{INTRODUÇÃO}

Este artigo versa sobre a Codicologia, como disciplina, e aborda algumas características visuais dos livros manuscritos, em especial árabes e persas, exploradas nesse campo de estudos. Essas características podem ser identificadas como uma cultura visual. Visita também algumas experiências de profissionais que desenvolveram atividades na Biblioteca Nacional da França, onde há um departamento específico para o cuidado e 
conservação de diversas coleções de livros manuscritos, originárias de várias culturas, como árabes e persas. Essas experiências têm intima relação com a Codicologia.

Esta disciplina, a Codicologia, que aqui chamo também de campo de estudos, visa, segundo François Déroche (2000, p. 12), "..., em primeiro lugar, conhecer na sua materialidade o codex (no plural em latim, codices), quer dizer, o livro construído a partir de uma junção [costura] de cadernos; digamos para simplificar que esta estrutura que define o objeto da Codicologia é aquela dos livros que nós utilizamos ainda em nossos dias, ainda que a imprensa tenha substituído a mão do copista." ${ }^{\text {i }}$

Segundo uma outra definição para a Codicologia, de Jacques Lemaire (1989, p. 2),

\begin{abstract}
Sem dúvida, o objetivo fundamental do ato de ler permanece o conhecimento do pensamento de um autor, ou nossa relação de simpatia com o mesmo. Todavia, a perfeita avaliação da mensagem de um escritor, conhecido ou anônimo, não pode se operar sem um olhar para o enveloppe exterior do objeto que, em todos os tempos, transmitiu a mensagem. Este objeto material, que se chama nos nossos dias livro, que levava nos primórdios o nome de codex, constitui a matéria fundamental da codicologia. Ciência nova, o estudo codicológico pretende propor uma arqueologia do livro, principalmente do livro manuscrito. Seu ar de pesquisa ultrapassa, entretanto, o campo do saber arqueológico, no sentido estrito desse adjetivo, para se dedicar a diversos aspectos do conhecimento histórico: história individual de um escrito considerado em sua unicidade, história da transmissão dos textos, história dos produtores de textos, história dos fundos, das bibliotecas, das coleções ou dos colecionadores. ${ }^{\text {ii }}$
\end{abstract}

Por essa definição podemos perceber parte da dimensão ou do alcance dos estudos da Codicologia. Dessas afirmações podemos extrair ensinamentos iniciais sobre essa nova disciplina que vem se estabelecendo formalmente desde o século XX, a partir de textos escritos por Alphonse Dain ${ }^{\text {iii }}$ (LEMAIRE, 1989, p. 1) e Charles Samaran ${ }^{\text {iv }}$ (LEMAIRE, 1989, p. 1), estudiosos franceses que reivindicam a paternidade do termo Codicologiav ${ }^{\mathrm{V}}$ (LEMAIRE, 1989, p. 1). No caso da Codicologia dos livros árabes, o desenvolvimento da disciplina é ainda mais recente.

A Codicologia busca fornecer elementos para a análise dessas fontes primárias: os livros manuscritos. Oferecer ferramentas para a interpretação histórica e para a tentativa de compreender as imagens contidas nas páginas, um exercício de leitura desses conjuntos visuais e das particularidades físicas desses livros.

A palavra Codicologia causa, num primeiro momento, dúvidas sobre seu significado ou a sua origem. Para analisarmos textos manuscritos dos códices ou de livros de outros formatos escritos à mão, lançamos mão de uma ferramenta que ainda está se desenvolvendo.

No caso dos livros manuscritos árabes, estes possuem uma marca de identidade visual característica que permite a associação imediata com a sua cultura, que são as letras do seu alfabeto. Porém, essas letras do alfabeto árabe são e foram utilizadas também em livros de outros povos, com culturas e línguas diversas, como persas, curdos, urdus, turcos, etc. Isso parece se tornar mais claro se fizermos uma simples analogia dos empregos do alfabeto árabe naquelas línguas citadas acima com os do alfabeto latino por diversas culturas e suas línguas, 
tão diferentes, mas compreensíveis para nós ocidentais. Ou incompreensíveis oralmente, mas acessíveis pelo recurso da escrita.

O elo de ligação dessas culturas com as letras do alfabeto árabe é, em geral, o livro sagrado dos muçulmanos, o Corão, que ao ser introduzido em diversos locais pela expansão do islamismo levou junto esse tipo de escritura. Dessa forma, talvez pudéssemos pensar ser mais correta a afirmação de que essa marca de identidade, esses sinais, estão ligados intimamente à religião muçulmana. Mas essa afirmação também não é totalmente verdadeira, pois há textos de todas essas línguas e de outras religiões como a cristã, a judaica e provavelmente outras, escritos com caracteres árabes. Essa marca, então, pode nos enganar. Há culturas e línguas a serem pensadas e analisadas.

\begin{abstract}
$\mathrm{O}$ aspecto material dos manuscritos orientais conservados na Europa se caracteriza pelo fato de que as marcas, as alterações e restaurações que eles carregam ou as mudanças que afetaram suas encadernações podem ter uma origem oriental ou ocidental, testemunho de suas diversas mudanças; para os estudar o pesquisador enfrentará problemas de codicologia tanto oriental quanto ocidental e deverá então fazer prova de pluridisciplinaridade, no que diz respeito ao conhecimento das obras de referência. O reconhecimento, decifração e identificação dessas marcas, orientais ou ocidentais, que podem parecer à primeira vista depender de análises muito específicas em razão das línguas e das escritas empregadas, estão de fato em relação constante, pois os problemas a resolver são, de um ponto de vista metodológico e técnico, muito próximos. ${ }^{\text {vi }}$ (BERTHIER, 2000, p. 367)
\end{abstract}

O livro sagrado dos muçulmanos, o Corão, assim como os livros laicos - ou sem pretensão de fazer apologia à religião - e os documentos manuscritos de chancelaria, administrativos, contábeis, etc, são fontes, objetos de estudos, que podem permitir a identificação de rastros e hábitos das diversas culturas que se submeteram ao islamismo pela observação de detalhes físicos visíveis concernentes à sua construção. "A prosa artística árabe propriamente dita nasceu ... dentro dos escritórios de chancelaria da administração."vii (SCHOELER, 2002, p. 61). Esses mesmos estudos demonstram, portanto, que devemos tomar cuidado antes de afirmar alguma coisa, já que esses estudos ainda podem ser considerados incipientes em Codicologia. Um campo de estudos, uma disciplina - dita auxiliar da História e de outras ditas ciências -, que pretende explicar os textos e os livros, embora ainda esteja na sua infância.

A palavra análise é fundamental e deve ser lembrada sempre que pensarmos na Codicologia pois esse campo de estudos não é restrito a uma descrição dos textos. Uma simples descrição poderia ser chamada de codicografia. Essa diferença repercute, por exemplo, nos catálogos de livros manuscritos da Biblioteca Nacional da França, em Paris. Uma diferença das informações das fichas dos livros dos diferentes catálogos, de diferentes momentos históricos, pode ser percebida na análise, mais ou menos minuciosa, feita em um determinado livro manuscrito. Essas descrições trazem consigo, em sua escrita, uma demonstração do nível de especialização atingido pelos profissionais que atuam nessa atividade de catalogação da referida biblioteca. E enfatizo aqui que não me refiro a conhecimento ou cultura gerais ou específicos desses profissionais. Não se trata aqui de julgar esse ou aquele autor de um catálogo como mais ou menos capaz, mas de perceber que 
houve uma agregação de conhecimentos codicológicos, técnicos, que repercutem nos detalhes apresentados nas fichas catalográficas.

Como exemplo segue abaixo a ficha catalográfica de um Corão, redigida por William de Slane num catálogo da Biblioteca Nacional da França publicado entre 1883 e 1885. A datação desse livro suscitou dúvidas diante de uma anotação no corpo do mesmo, indicando que fora presente do califa Harun al-Raschid ao imperador Carlos Magno.

\section{Manuscrito Oriental n. 399}

Corão em escrita cúfica.

Na sequência da última surata se acha uma nota, traçada em caracteres cúficos e de uma escrita mais moderna que o corpo da obra ... «Escrito sob ordem do Comandante dos crentes, a quem Deus perpetue o reino, o califa Haroûn al-Raschid, à quem Deus seja favorável, assim como a seus ancestrais, os puros; no mês de ramadhân do ano 182 (798 de J. C.).» Esta inscrição deu lugar à crença de que nosso ms. [manuscrito] fazia parte de um presente que o califa Haroûn al-Raschid tinha enviado a Charlemagne. Um exame atento do ms., de sua escrita, de sua encadernação e do estojo que o encerra, nos autoriza a repudiar esta lenda:

$1^{\circ} \mathrm{A}$ escrita do ms. assemelha-se àquela das moedas cúficas do século IX e seu frescor, assim como a brancura das folhas não permite olhá-la como mais antiga que esta época.

$2^{\circ}$ As folhas são numeradas em cifras indianas, da forma daquelas que se observa nos mss. dos séculos XVI e XVII.

$3^{\circ} \mathrm{O}$ ms. foi reparado no Oriente, sem dúvida no século XVI.

$4^{\circ}$ A encadernação do ms. é evidentemente oriental e do século XVI.

$5^{\circ} \mathrm{O}$ estojo em pele, feito deliberadamente para este ms., leva sobre a dobra a inscrição ordinária em naskhi moderno: ... [texto em árabe]

$6^{\circ}$ Dentro do estojo se lê: "Ex munificentia magistri Cochu, 1787."

$7^{\circ}$ A nota árabe feita no texto foi juntada numa época muito recente, como é fácil de o reconhecer pela cor da tinta e pelas formas pouco arcaicas de várias letras.

$8^{\circ}$ A fórmula empregada, falando do califa: "a quem Deus seja favorável, assim como a seus ancestrais, os puros," pertence ao rito xiita e não poderia ser aplicada a um califa abássida.

Resulta dessas indicações que o volume é do século IX ou X; que ele foi emendado e encadernado no Oriente no século XVI; que ele recebeu sua paginação no século XVII, que no ano 1787 ele se achava entre as mãos de um Europeu e que a Biblioteca do Rei só pode adquiri-lo posteriormente a esta data.

O texto desse ms. não oferece outras divisões além daquela em grupos de dez versículos; ele é desprovido de pontos diacríticos. Os pontos vermelhos, localizados tanto no meio das linhas quanto em cima ou em baixo das palavras, marcam as hamza e mesmo alguns movimentos. Eles parecem ter sido acrescidos depois .

Pergaminho. 369 folhas. Altura, 4 centímetros; largura, 7 centímetros e meio, 11 linhas por página; - (Suplemento 114). ${ }^{\text {viii }}$ (SLANE, 1883-1895, p. 120)

Essa ficha catalográfica apresenta diversas indicações de aspectos visuais do livro que foram observados por Slane para sustentar suas afirmações de negação da anotação referente à doação do livro, de Harun al-Raschid a Carlos Magno, e demonstram uma cultura visual, o conhecimento das línguas, culturas e religião envolvidas, além dos aspectos codicológicos, como tipos de encadernações, de tintas, etc.

Os formatos dos livros antigos, em rolo, anteriores ao codex, foram o volumen e o rotulus. O primeiro se caracteriza por ter sua escrita disposta em linhas perpendiculares ao 
eixo de desenrolamento do rolo e o segundo pela escrita paralela ao eixo ${ }^{\text {ix }}$ (DÉROCHE, 2000, p. 13-14).

Paralelamente, mas não obrigatoriamente, essa mudança foi acompanhada pela alteração do tipo de suportes utilizados, do papiro para o pergaminho. $\mathrm{O}$ uso de pergaminho nos livros é registrado em Roma no século I d.C. ${ }^{x}$ (IRIGOIN, 1998, p. 4). Esses suportes, entretanto, conviveram por um bom tempo. Essa transformação, do rolo para o codex, implicaria também numa mudança de hábitos, diante da manipulação e do transporte mais fáceis do objeto de leitura.

\begin{abstract}
O sucesso do codice foi garantido por diversas facilidades que esse oferecia, como a economia de material de escrita, já que o codice vinha escrito sobre as duas faces da página, diferentemente do rotulus, escrito normalmente sobre uma só face; a elevada praticidade de manejo e de uso, já que podia ser segurado e lido com uma só mão ou sobre um confortável atril; a capacidade, já que o codice podia conter uma extensão textual muito mais ampla que a do rotulus e também de incluir mais livros de uma mesma obra. . . ${ }^{x i}$ (CAVALLO, 2008, p. 12)
\end{abstract}

O codex, com esse formato que chegou até nós, baseia-se na reunião de cadernos formados a partir da dobra de folhas por quantas vezes forem necessárias para se chegar ao tamanho desejado da página do livro. Isso se aplica a códices cujas matérias-primas são o pergaminho ou o papel, que surgiria posteriormente. Os códices de papiro eram feitos pela colagem das folhas recortadas de um rolo previamente preparado, no tamanho desejado do futuro livro.

Embora existam diversos formatos de livros, como os citados acima, a Codicologia se dedica ao estudo de todos os livros manuscritos, inclusive dos fragmentos dos mesmos, já que muitos estão incompletos nas bibliotecas que possuem coleções de origem antiga ou medieval. Esses fragmentos oferecem também ricas informações para pesquisadores.

\title{
2 CULTURA CODICOLOGICA
}

A análise dos livros manuscritos começa pela observação geral do objeto, das características físicas visíveis como as que seguem:

- as medidas de altura e largura do livro;

- o formato: horizontal ou vertical;

- o tipo de caligrafia utilizada pelos artesãos do livro - como os copistas - que pode ajudar a identificar a escola caligráfica bem como o local de produção - um monastério no ocidente latino ou uma biblioteca árabe, persa, turca, de uma madrassa ou de uma mesquita, no oriente islâmico - , onde se exercia esse tipo de trabalho, como num ateliê, com um mestre que coordenava um grupo de copistas;

- as características subjetivas dessas caligrafias, que podem ajudar a identificar um mestre calígrafo, antes da escola caligráfica, mais geral;

- as pinturas nos livros que representam algo, de forma literal ou não, e que permitem a identificação, mais uma vez subjetiva, de autores ou escolas de pintura tradicionais; 
- o pautado e o espaço entre as linhas e entre as letras, além da disposição desses textos nas páginas;

- os espaços das margens e as anotações e/ou observações nas mesmas;

- as observações (glosas) e suas características, que permitem identificar e datar, por exemplo, comentários e análises exegéticas quando for o caso.

- as encadernações, que são o fecho do processo de fabricação do livro e que podem identificar parte dos caminhos percorridos pelo mesmo;

- as páginas de título;

- as marcas de posse, que também ajudam a demonstrar esse caminho percorrido pelos livros.

Um recurso importante para a datação do manuscrito é a utilização de provas laboratoriais como, por exemplo, a análise de carbono 14.

Além disso, é fundamental o conhecimento da cultura e a história do livro e das pessoas que o envolvem, como os autores, os doadores, os artesãos, os calígrafos, pintores, miniaturistas, artistas que envolvem a preparação do livro a ser analisado, como ficou claro na ficha catalográfica apresentada acima, preparada pelo Barão De Slane.

Existem também características físicas menos visíveis a olho nu, como as filigranas ou marcas d'água, que requerem a utilização de uma fonte de luz natural ou artificial atrás da folha para a observação dessas marcas dos fabricantes. "Esta marca, visível sobre cada folha, empresta frequentemente suas formas à heráldica; ela é às vezes acompanhada de letras."xii (DÉROCHE, 2000, p. 63). As filigranas permitem a identificação do local e da data de produção do papel pela comparação com catálogos de filigranas como o de Charles-Moïse Briquet, Les filigranes. Dictionnaire historique des marques du papier dès leur apparition vers 1282 jusqu'en 1600; Avec 39 figures dans le texte et 16,112 fac-similés de filigranes. Nessa obra Briquet faz algumas perguntas e tenta respondê-las através de um catálogo sistemático de filigranas. Essas perguntas são as mesmas que devemos ou podemos fazer como ponto de partida para uma pesquisa, adaptadas ao tema de pesquisa, à cultura, aos povos, aos países, etc, a serem abordados:

\footnotetext{
$1^{\circ}$ A que época remontava na Suíça o uso do papel?

$2^{\circ}$ Em quais lugares se estabeleceram neste país os primeiros batedores de papel e qual a data de sua fundação?

$3^{\circ}$ Quais são as filigranas e de onde vinham os papéis empregados antes da existência das fábricas de papel indígenas? ${ }^{\text {iiii }}$ (BRIQUET, 1923, p. XVIII)
}

As questões de Briquet, relativas a seu país, permitem identificar com clareza algumas das possibilidades - e impossibilidades - de pesquisa das filigranas nos papéis. A identificação dos fabricantes se tornou mais precisa depois do século XVI quando esses começaram a utilizar uma outra marca na folha, no lado oposto ao da filigrana, com iniciais, desenhos, etc, ajudando na datação do papel. Porém, é importante salientar que com o aparecimento de falsificações e variações, a identificação dos fabricantes pelas filigranas é um procedimento difícil, demorado, que requer muita paciência e conhecimento; uma cultura visual, aliada à consulta de repertórios, bases de dados e catálogos. Briquet mesmo alerta que "...teóricamente, toda folha de papel filigranada leva nela mesma sua certidão de nascimento, 
a marca que lhe permite fazer conhecer a data e o lugar de sua fabricação. Mas na prática, nós só conseguimos decifrar essa certidão de nascimento de uma maneira aproximada, por que nos faltam dados indispensáveis para a ler."xiv (BRIQUET, 1923, p. XVIII)

Essas observações são fundamentais no estudo dos livros manuscritos, segundo Annie Berthier, conservadora honorária da Biblioteca Nacional da França, que escreve sobre a necessidade da pesquisa prática neste campo de estudos, a codicologia:

\begin{abstract}
Uma reprodução, mesmo excelente, não permite conhecer a cor precisa de um suporte (papiro, papel ou pergaminho), medir a densidade, examinar por transparência, determinar sua superfície; a partir de uma reprodução, é impossível apreciar uma página na sua espessura para detectar a presença de colagens ou de decupagens, de bem observar as raspagens nem de medir o formato do volume, contar os cadernos, conhecer a natureza de sua costura; é difícil de estudar o pautado, as tintas, analisar as retomadas de pena, as passagens alteradas ou apagadas. Pode-se então dizer que a descrição codicológica completa de um volume só pode ser fundada sobre exame de um original. ${ }^{\mathrm{xv}}$ (BERTHIER, 2000, p. 21)
\end{abstract}

E ainda observando os registros das experiências práticas de outros profissionais além dela, de Charles-Moïse Briquet e do Barão William De Slane, temos também a coleção de livros manuscritos persas.

No caso desta, quem nos dá informações sobre seu desenvolvimento é Francis Richard, que foi conservador do Departamento de Manuscritos Orientais da Biblioteca Nacional da França, de 1974 a 2003 e depois diretor do Departamento de Artes do Islã do Museu do Louvre. Hoje ele é Diretor Científico da BULAC - Biblioteca Universitária de Línguas e Civilizações, de Paris:

\begin{abstract}
... a Biblioteca real não parece ter possuído livro em persa antes dos anos 1660. Não encontramos, em todo caso, nenhum traço nos inventários conservados. ... Prolongamento para o Oriente do movimento humanista do Renascimento, a busca pelos textos orientais, onde se pensava poder encontrar as traduções dos textos perdidos da Antiguidade, tinha se iniciado na França nos primeiros anos do século XVI. Começam naquela época a se interessar pelo Irã, sua língua e sua literatura. ${ }^{\text {xvi }}$ (RICHARD, 1989, p. 1)
\end{abstract}

Os livros manuscritos persas têm uma estética original, muitos deles possuindo imagens. E as imagens desses livros são, no mínimo, bastante diferentes daquelas que nos acostumamos a ver nos livros e pinturas ocidentais.

\footnotetext{
Parece-nos, com efeito, que para 'olhar' essas pinturas, nos falta entrar com simplicidade num sistema estético diferente do nosso (consideramos por 'nosso' um modo de ver dito 'ocidental', fundado sobre leis e critérios herdados do Renascimento), no qual as representações picturais 'transcrevem as imagens mentais manifestadas no texto pela poesia ou a prosa' e onde as cores são primeiro um código em relação direta com as metáforas literárias, mesmo se elas se acham enriquecidas no curso do tempo por metáforas picturais acrescentadas pelas pinturas mesmo. ${ }^{\text {xvii }}$ (BERTHIER, 1991, P. 116)
}

Na ficha catalográfica do Suplemento Persa 1, elaborada por Francis Richard no Catálogo de Manuscritos Persas e reproduzida na próxima página, pode-se observar o 
resultado de uma análise textual e codicológica. $\mathrm{O}$ autor faz inclusive indicações bibliográficas de textos que retratam o manuscrito descrito.

O resultado de uma primeira análise de aspectos codicológicos e textuais de um manuscrito é encontrado nos catálogos elaborados nas bibliotecas, com esse objetivo exato de dar suporte às pesquisas que ali serão desenvolvidas.

Suplemento persa 1

ZABŪR. Versão judeu-persa dos Salmos, transcrita em caracteres árabes.

Trata-se de um texto transcrito segundo três manuscritos em caracteres hebreus (f. $247 \mathrm{v}, 248-9 \mathrm{v})$, dos quais dois provém de Lār e um de Šīrāz. Um dos ms. de Lār fornece o texto de base. O mais antigo dos três ms., o de Šīrāz, datava aproximadamente de 1316. Giovan Battista Vecchietti [, que era ajudado especialmente pelo rabino Abrahan Zabolon de Lār], ditou ao copista o texto dos Salmos. As variantes dadas pelo ms. de Šīrāz são em vermelho; as do segundo ms. de Lār em negro. Este trabalho foi efetuado (cf. f. 248-9v) entre 3 de outubro 1600 e 12 de maio de 1601. Cada salmo leva o título de faṣl (capítulo).

5 linhas seguintes com textos em árabe

Bibl.: [lista de textos com referências a esse manuscrito] Asmussen 1989, p. 208-9; Piemontese Italia, $\mathrm{n}^{\circ} 233$, p. 199-200; Pimontese 2007, p. 385-409; Richard 1980a, p. 291-300; Richard 2005, p. 11-16.

1600 (3 outubro) - 1601 (12 de maio). Cópia acabada (colofão do f. 247v), sob o ditado de G. B. Vecchietti «o Franco» (Farangī), 12 de maio de 1601 A.D. na ilha de Jārūn - quer dizer de Hormūz - $\quad$ por Šams al-Dīn b. Qutb al-Dīn Qalātī] Hunjī [, igualmente copista dos ms. Suplemento persa 4, 725 e 799 da BnF, assim como do ms. III-G-34 da B. N. de Nápoles descrito por Piemontese, o.c., $\mathrm{n}^{\circ} 233$, que é uma cópia desses mesmos Salmos tendo a mesma data, mas com revisão do texto por Abraham Zabolon]

Escrita persa nashī de 10 linhas por página (sem contar as variantes, inscritas em nasta'lī $q$ entre as linhas); títulos rubricados; reclames; superfície escrita 100x190 mm. Ms. de 160x250.

Pautado por mistara.

Papel oriental marfim com fibras espessas e vergaduras incurvadas (20 vergaduras ocupam em torno de $26 \mathrm{~mm}$ ), perpendiculares à costura. 249 folhas. Cadernos: binion (f. 1-4), depois f. 5 inserida antes de 30 quaternions (f. 6-245), seguidos da f. 246, inserida, et de um binion final.

As f. $1 \mathrm{v} .-2 \mathrm{v}$ e 4-6 permaneceram brancas.

Ms. copiado por G.B. Vecchietti (1552-1618) que fez uma grande nota em italiano nas f. 248-9v [publicada por F. Richard, 1980, p. 295-6] e a assinou (f. 248); foi relatado por ele em italiano em 1609. Na f. 1 figuram um $n^{\circ} \ll 20 »$ em cifras persas et um $\mathrm{n}^{\circ} \ll 80 »$. No contraplano está colada uma etiqueta onde os números «20»e «80» são bloqueados. Talvez o ms tenha passado entre as mãos de Barthélemi d'Herbelot de Molainville (1625-1695). Ele tem o ex-libris do abade Eusèbe Renaudot (1645-1720) no contraplano e na f. 1, assim como uma nota latina de sua mão na mesma f. 1. Ele foi legado em 1720 (cf. etiquetae da f. 249v) na Biblioteca do abade de St. Germain-des-Prés e entrou na B.N. em 1796 por causa dos confisco revolucionários. [Antiga Cota St. Germain N. 514].

Encadernação persa com cobertura em marroquim castanho-escuro estampado à frio por uma placa central em mandorla polilobada (52x37 mm; décor de type Osh 7) de florões (realizadas por repetição em três retomadas do mesmo ferro), de cantos e de bordas de quatro filetes. Forros de pleno marroquim vermelho com dupla borda de filetes e decoração central (o mesmo ferro que aquele dos florões dos pratos sendo quatro vezes) estampados à frio. ${ }^{\text {xviii }}$ (RICHARD, 2013, p. 35) 
Outro detalhe da cultura visual que é abordado na análise codicológica e que é tema essencial dessa é o que trata da introdução da vocalização nos textos em árabe dos livros manuscritos. Num período de nascimento do islã a língua escrita estava sendo aperfeiçoada por esses sinais com o objetivo de aproximar duas formas de difusão da mesma, oral e escrita; isso acontece no final do primeiro século da Hégira, segundo a tradição, e pode ser visto como uma demonstração de uma disputa entre esses dois modelos ${ }^{\text {xix }}$ (CELLARD, 2015, p. 152).

Num artigo publicado recentemente, Christian Julien Robin tenta fazer uma análise histórica de algumas Suratas do Corão utilisando-se de várias fontes, como o texto corânico em si, traduções respeitadas do mesmo, trabalhos arqueológicos atualizados, etc. Como já dito anteriormente, respostas definitivas não existem. Numa passagem desse texto ele reproduz uma dessas dificuldades da pesquisa com os textos corânicos apresentando uma observação feita por Régis Blachère em sua tradução de $1966^{\mathrm{xx}}$ (ROBIN, 2015, p. 28). Na Surata 30, chamada 'Os Romanos', por conta da falta de vocalização, indicada na língua árabe pelo acréscimo de sinais acima ou abaixo das consoantes, a leitura do verbo pode ser entendida na voz passiva ou na voz ativa. Mas essa indicação da vocalização veio posteriormente. $^{\mathrm{xxi}}$ (ROBIN, 2015, p. 28)

Retornando aos comentários de Annie Berthier sobre a diferença das imagens persas em relação às nossas, ocidentais, ela nos coloca diante de algumas questões de difícil resposta, senão impossíveis, que fazem com que o objetivo da codicologia torne-se mais distante. As imagens persas sobre as quais essa autora escreve têm uma perspectiva totalmente diferente daquela das imagens ocidentais, que nós conhecemos, e essas últimas poderiam ser descritas, ouso dizer, como já analisadas por todos nós. Explico melhor: temos uma cultura visual que nos faz 'entender' as imagens com essa perspectiva convencional, sejamos leitores ou não de textos ou tratados sobre o assunto. A perspectiva está posta diante de nós desde que nascemos, nas fotografias, por exemplo; não é preciso que frequentemos a academia para conhecê-la.

Isso pode causar desconforto aos leitores desse texto, mas esse mal-estar ou essa perturbação que podem acompanhar a visão dessas imagens exóticas - para nós, ocidentais podem ser consideradas partes integrantes da leitura de textos poéticos, algo que será encontrado constantemente durante análises codicológicas.

Uma resposta possível para essas dificuldades de compreensão das imagens que acompanham os textos persas, além dos próprios, é dada pela mesma autora: "E se 'o erro' das perspectivas [persas] era simplesmente metafórico, simbólico?" Será que a perspectiva europeia, onde os pontos de fuga direcionam o nosso olhar, não proíbe que vejamos a cena de outra forma? $^{\text {xxii }}$ (BERTHIER, 1991, p. 24) 


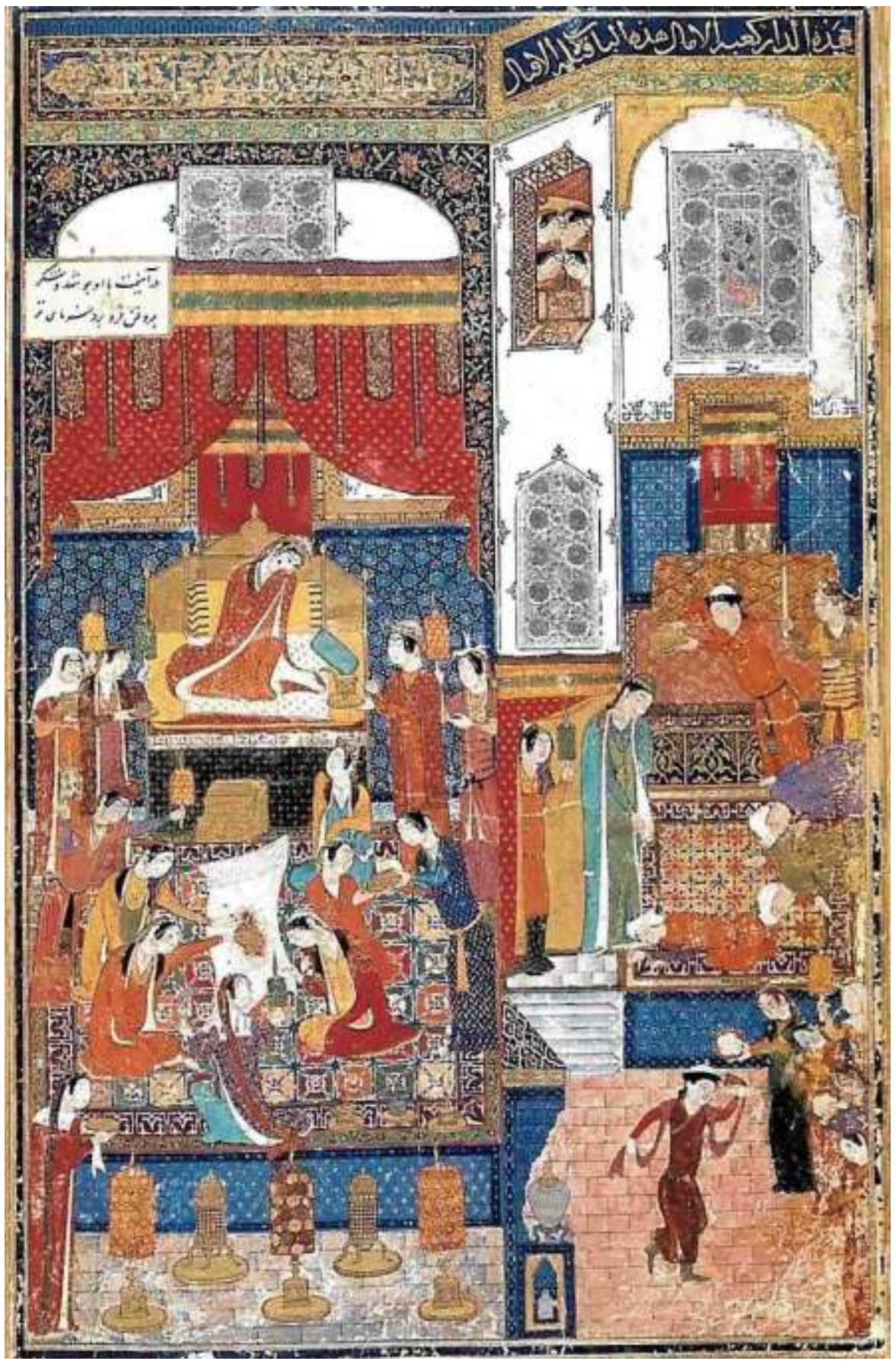

Fonte : (GRABAR, 2000, p. 55. "Junayd, O casamento de Humay e Humayun, do Divan de Khwaju Kirmani, 1396 [799], British Library, Londres... composição com a cor vermelha dominante na qual todos os episódios de um casamento, da consumação sexual à dança, são igualmente descritos ou simbolizados."

A análise codicológica também não é uma atividade simples, bem pelo contrário. Suscita diversos tipos de contradições. Entre os estudiosos da religião que têm opiniões diferentes entre si sobre o texto do Corão e que são reproduzidas nas diferentes possibilidades de leitura e recitação do mesmo; entre os estudiosos da religião e os acadêmicos; entre os acadêmicos entre si, que naturalmente desenvolvem teorias, mais ou menos plausíveis de acordo com a leitura que fazem de suas fontes e que tentam chegar a uma interpretação 
imparcial, que penso ser quase impossível. A língua escrita é o centro dessas pesquisas e a análise codicológica uma ferramenta importante.

Ainda sobre as coleções de livros, comuns nas grandes bibliotecas, Donatella Nebbiai comenta sobre a relação entre os nomes dessas coleções, os antigos proprietários - pessoas ou instituições - que originaram esses fundos e a história dessas bibliotecas, como a Nationale de France (Paris), a British Library (Londres), a Bodleian Library (Oxford) ou a Apostolica Vaticana (Roma) ${ }^{x i i i i}$ (NEBBIAI, 2005, p. 13). Ouso extender essa relação com a história dos países que as sediam, já que esses personagens ou instituições geralmente estavam a serviço deles. Muitas das pessoas que formaram essas coleções foram enviados oficialmente a trabalho a outros países para exercerem ocupações em órgãos diplomáticos e, por seu interesse pessoal, desenvolveram essa atividade intelectual.

Para concluir gostaria de lembrar algumas poucas palavras de Paul Géhin no livro que organizou com o sugestivo título a seguir: Lire le manuscrit médiéval. Observer et décrire ${ }^{x x i v}$ (GÉHIN, 2005, p. 7). Ele relacionou o objetivo do conjunto de textos desse livro com a cultura visual e escreveu: "É então a uma educação do olhar que é destinada esta obra."

\section{REFERÊNCIAS}

BERTHIER, Annie. Codicologie et histoire des fonds. In: DÉROCHE, François. Manuel de codicologie des manuscrits en écriture arabe. Paris: Bibliothèque Nationale de France, 2000, p. 366-376.

BERTHIER, Annie. Qalams, pinceaux, ciseaux. Ombres chinoises sur la miniature persane et turque. Revue Etudes Orientales, n. 11-12. 1991, p. 116-125. ISSN 2077-4079.

BRIQUET, Charles-Moïse. Les filigranes. Dictionnaire historique des marques du papier dès deur apparition vers 1282 jusqu'en 1600; Avec 39 figures das le texte et 16,112 facsimilés de filigranes. Leipzig: Verlag von Karl W. Hiersemann, 1923.

CAVALLO, Guglielmo. Del rotolo ao codice e di altri aspetti della cultura scritta antica e medievale. In: ARDUINI, Franca. La forma del libro. Dal rotolo al codice (secoli III a.C.XIX d.C.). Firenze: Mandragora, 2008.

CELLARD, Éléonore. La vocalisation des manuscrits coraniques dans les premiers siècles de l'islam. In: DÉROCHE, François; ROBIN; Christian Julien; ZINK, Michel éd. Les origines du Coran, le Coran des origines. Paris: Académie des Inscriptions et Belles-Lettres, 2015, p. 151-176.

DÉROCHE, François. Manuel de codicologie des manuscrits en écriture arabe. Paris: Bibliothèque Nationale de France, 2000.

GÉHIN, Paul. Lire le manuscrit médiéval. Observer et décrire. Paris: Armand Colin, 2005.

GRABAR, Oleg. Mostly miniatures. An introduction to persian painting. Princeton: Princeton University Press, 2000. 
IRIGOIN, Jean. Les cahiers des manuscrits grecs. In: HOFFMAN, Philippe.

Recherches de codicologie comparée. La composition du codex au Moyen Âge, en Orient et en Occident. Paris: Presses de l'École Normale Supérieure, 1998.

LEMAIRE, Jacques. Introduction à la codicologie. Louvain-la-Neuve: Institut d'etudes médievales, 1989.

NEBBIAI, Donatella. Pour le signalement du manuscrit: cotes de bibliothèque. In: GÉHIN, Paul. Lire le manuscrit médiéval. Observer et décrire. Paris: Armand Colin, 2005, p. $10-14$.

RICHARD, Francis. Catalogue des manuscrits persans. I - Anciens fonds. Paris: Bibliothèque Nationale, 1989.

RICHARD, Francis. Catalogue des manuscrits persans. Bibliothèque Nationale de France. Département des manuscrits. Tome II. Le supplément persan. Première partie. Supplément persan, 1 à 524. Roma: Istituto per l'Oriente C. A. Nallino, 2013.

ROBIN, Christian Julien. L'Arabie dans le Coran, réexamen de quelques termes à la lumière des inscriptions préislamiques. In: DÉROCHE, François; ROBIN; Christian Julien; ZINK, Michel éd. Les origines du Coran, le Coran des origines. Paris: Académie des Inscriptions et Belles-Lettres, 2015, p. 27-74.

SCHOELER, Gregor. Écrire et transmettre dans le débuts de l'islam. Paris: PUF, 2002.

SLANE, William Mac Guckin de. Catalogue des Manuscrits Arabes (par M. Le Baron de Slane). Paris: Imprimerie Nationale, 1883-1895.

\footnotetext{
i DÉROCHE, François. Manuel de codicologie des manuscrits en écriture arabe. Paris: Bibliothèque Nationale de France, 2000, p. 12. As traduções dos textos são minhas.

ii LEMAIRE, Jacques. Introduction à la codicologie. Louvain-la-Neuve: Institut d'etudes médievales, 1989 , p. 02. iii Apud LEMAIRE, Jacques. Introduction à la codicologie. Louvain-la-Neuve: Institut d'etudes médievales, 1989, p. 01. [Cf. A. DAIN, Les manuscrits, Paris, Les Belles Lettres, 1964, p. 76. O autor escreve: «A palavra é nova em francês e eu reivindico a paternidade. Ela tem seu lugar, doravante depois de 1959, no Grand Larousse encyclopédique, e foi adotada e transcrita em diversas línguas de erudição». O Sr. Jean Vezin me informa que Charles Samaran tinha pensado em denominar a «ciência do manuscrito» pelo vocábulo codicografia, como em paleografia. Mas Mario Roques, o colega de Ch. Samaran na Ecole pratique des Hautes Etudes, tendo julgado esse neologismo inadequado, codicografia, durante muito tempo não foi considerada. O Sr. Albert Gruijs, entretanto, lhe deu recentemente algum crédito].

iv Apud LEMAIRE, Jacques. Introduction à la codicologie. Louvain-la-Neuve: Institut d'etudes médievales, 1989, p.1. [M. Gibert Ouy relata: «(...) é só recentemente que a arqueologia do livro manuscrito se contituiu como uma disciplina autônoma. O Sr. Charles Samaran lhe deu no seu curso na Ecole des Hautes Etudes o nome um pouco rebarbativo/ antipático, mas cômodo, de codicologia, sob o qual ele é agora designado». Cf. G. OUY, Les bibliothèques, dans L'histoire et ses méthodes, Paris, Gallimard, 1961, p. 1088.].

${ }^{v}$ LEMAIRE, Jacques. Introduction à la codicologie. Louvain-la-Neuve: Institut d'etudes médievales, 1989 , p. 01.

${ }^{v i}$ BERTHIER, Annie. Codicologie et histoire des fonds In: DÉROCHE, François. Manuel de codicologie des manuscrits en écriture arabe. Paris: Bibliothèque Nationale de France, 2000, p. 367.

vii SCHOELER, Gregor. Écrire et transmettre dans le débuts de l'islam. Paris: PUF, 2002, p. 61.

viii SLANE, William Mac Guckin de. Catalogue des Manuscrits Arabes (par M. Le Baron de Slane). Paris: Imprimerie Nationale, 1883-1895, p.120.

ix DÉROCHE, François. Manuel de codicologie des manuscrits en écriture arabe. Paris: Bibliothèque Nationale de France, 2000, pp. 13-14.
} 
x IRIGOIN, Jean. Les cahiers des manuscrits grecs. In: HOFFMAN, Philippe. Recherches de codicologie comparée. La composition du codex au Moyen Âge, en Orient et en Occident. Paris: Presses de l'École Normale Supérieure, 1998, p. 4.

xi CAVALLO, Guglielmo. Del rotolo ao codice e di altri aspetti della cultura scritta antica e medievale. In: ARDUINI, Franca. La forma del libro. Dal rotolo al codice (secoli III a.C.-XIX d.C.). Firenze: Mandragora, 2008, p. 12.

xii DÉROCHE, François. Manuel de codicologie des manuscrits en écriture arabe. Paris: Bibliothèque Nationale de France, 2000, p. 63.

xiii BRIQUET, Charles-Moïse. Les filigranes. Dictionnaire historique des marques du papier dès deur apparition vers 1282 jusqu'en 1600; Avec 39 figures das le texte et 16,112 fac-similés de filigranes. Leipzig: Verlag von Karl W. Hiersemann, 1923. (Déuxième edition), p. XII.

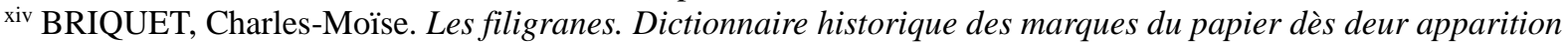
vers 1282 jusqu'en 1600; Avec 39 figures das le texte et 16,112 fac-similés de filigranes. Leipzig: Verlag von Karl W. Hiersemann, 1923. (Déuxième edition), p. XVIII.

xv BERTHIER, Annie. In: DÉROCHE, François. Manuel de codicologie des manuscrits en écriture arabe. Paris: Bibliothèque Nationale de France, 2000, p. 21.

xvi RICHARD, Francis. Catalogue des manuscrits persans. I - Anciens fonds. Paris: Bibliothèque Nationale, 1989, p. 1.

xvii BERTHIER, Annie. Qalams, pinceaux, ciseaux. Ombres chinoises sur la miniature persane et turque. Revue Etudes Orientales $\mathrm{n}^{\circ}$ 11/12 Hiver/ Printemps 1991, p. 116.

${ }^{\text {xiii }}$ RICHARD, Francis. Catalogue des manuscrits persans. Bibliothèque Nationale de France. Département des manuscrits. Tome II. Le supplément persan. Première partie. Supplément persan, 1 à 524. Roma: Istituto per l'Oriente C. A. Nallino, 2013, p. 35.

xix CELLARD, Éléonore. La vocalisation des manuscrits coraniques dans les premiers siècles de l'islam. In: DÉROCHE, François; ROBIN; Christian Julien; ZINK, Michel éd. Les origines du Coran, le Coran des origines. PARIS: Académie des Inscriptions et Belles-Lettres, 2015, p. 152.

${ }^{\mathrm{xx}}$ Apud ROBIN, Christian Julien. L'Arabie dans le Coran, réexamen de quelques termes à la lumière des inscriptions préislamiques. In: DÉROCHE, François; ROBIN; Christian Julien; ZINK, Michel éd. Les origines du Coran, le Coran des origines. PARIS: Académie des Inscriptions et Belles-Lettres, 2015, p. 28.

"Esses são os famosos versículos no começo da Surata 30 [«Os Romanos», al-Rūm]/ [1-2] 2-3:

Leitura comum: «[1] 2

«Os "Romanos" foram vencidos nos confins de nossa terra.

[2] 3 [Mas] eles, após sua derrota serão vencedores,

[3] 4 em alguns anos»

Variante:

[1] 2 «s "Romanos» venceram nos confins de nossa terra.

[2] 3 [Mas] eles, após sua vitória, serão vencidos

[3] 4 em alguns anos.» (Blachère 1966, p. 429-430)."

${ }^{x x i}$ ROBIN, Christian Julien. L'Arabie dans le Coran, réexamen de quelques termes à la lumière des inscriptions préislamiques. In: DÉROCHE, François; ROBIN; Christian Julien; ZINK, Michel éd. Les origines du Coran, le Coran des origines. PARIS: Académie des Inscriptions et Belles-Lettres, 2015, p. 28.

xxii BERTHIER, Annie. Qalams, pinceaux, ciseaux. Ombres chinoises sur la miniature persane et turque. Revue Etudes Orientales n ${ }^{\circ}$ 11/12 Hiver/ Printemps 1991, p. 124.

xxii NEBBIAI, Donatella. Pour le signalement du manuscrit: cotes de bibliothèque. In: GÉHIN, Paul. Lire le manuscrit médiéval. Observer et décrire. Paris: Armand Colin, 2005, p. 13.

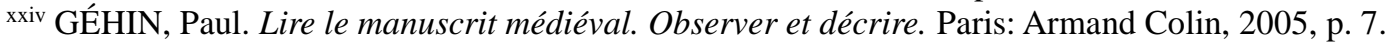




\section{AGRADECIMENTOS}

O desenvolvimento da pesquisa que resultou nesse texto foi possível graças ao apoio da Coordenação de Aperfeiçoamento de Pessoal de Nível Superior - CAPES, a quem agradeço, como bolsista do Programa Ciência sem Fronteiras.

UBIRAJARA ALENCAR RODRIGUES

Doutor em Educação

Universidade Estadual de Campinas - UNICAMP

Campinas, SP - Brasil

Documentalista da Faculdade de Educação,

Universidade Estadual de Campinas - UNICAMP

Campinas, SP - Brasil - E-mail: ubirajar@unicamp.br.

Recebido em: 10/11/2015

Aprovado para publicação em: 01/05/2016

\section{Como citar este documento:}

RODRIGUES, Ubirajara Alencar. Codicologia, história e cultura. ETD - Educação Temática Digital,

Campinas, SP, v. 18, n. 3, p. 614-627, jul. 2016. ISSN 1676-2592. Disponível em:

<http://periodicos.sbu.unicamp.br/ojs/index.php/etd/article/view/8641656>. Acesso em: 30 ago. 2016.

doi:http://dx.doi.org/10.20396/etd.v18i3.8641656. 